\title{
Equilibrium headspace analysis of volatile flavor compounds extracted from soursop (Annona muricata) using solid-phase microextraction.
}

\begin{abstract}
The influence of headspace solid-phase microextraction (HS-SPME) variables, namely, sample concentration, salt concentration and sample amount, on the equilibrium headspace analysis of the main volatile flavor compounds released from soursop was investigated. A total of 35 volatile compounds, comprising 19 esters, six alcohols, three terpenes, two acids, two aromatics, two ketones and an aldehyde, were identified. The results indicated that all response-surface models were significantly $(\mathrm{p}<0.05)$ fitted for 10 target volatile flavor compounds. The results further indicated that more than $65 \%$ of the variation in the equilibrium headspace concentrations of target volatile flavor compounds could be explained by the final reduced models, with high R2 values ranging from 0.658 to 0.944 . Multiple optimization results showed that extraction using a $76.6 \%(\mathrm{w} / \mathrm{w})$ sample concentration, $20.2 \%(\mathrm{w} / \mathrm{w}$ ) salt and $8.2 \mathrm{~g}$ of blended soursop pulp was predicted to provide the highest overall equilibrium headspace concentration for the target soursop volatile flavor compounds.
\end{abstract}

Keyword: Headspace solid-phase microextraction; Equilibrium headspace analysis; Volatile flavor compounds; Soursop; Response-surface model. 